\title{
A simple way of avoiding feed wastage in European seabass, Dicentrarchus labrax, under self-feeding conditions
}

\author{
Denis Coves $^{(*)}$, Eric Gasset, Gilles Lemarié, Gilbert Dutto \\ Station expérimentale d'aquaculture Ifremer, 34250 Palavas-les-Flots, France.
}

Received November 14, 1997; accepted November 18, 1998.

\begin{abstract}
Self-feeding systems allow fish to freely express feeding activity. A simple rod at the water surface can act as a trigger and provide fish with a way of obtaining pellets from a feeder. Such a rod presented to experienced European seabass, Dicentranchus labrax, may lead to feed wastage, probably as a result of unintentional fish contacts with the trigger. Trigger protection screens have been designed to prevent fish contacting the trigger by chance, and the efficacy of such screens was tested. Nocturnal and diurnal feed delivery and feed wasted were compared under conditions where the rod was unprotected or protected by semi-cylindrical or cylindrical screens. Tests were conducted using an unrestricted self-feeding regime (reward: $0.2 \mathrm{~g}$ pellet per $\mathrm{kg}$ of body weight and per fish contact) in juvenile seabass ( $57 \mathrm{~g}$ body weight) fed for 28 days at $21.3^{\circ} \mathrm{C}$. Fish were subjected to a 4-h L:20-h D (light:dark) photoperiod. The daily feed demand pattem and the nocturnal and diurnal feed wastage were recorded. Fish activated the trigger predominantly at night, except in the case of one group exposed to a trigger protected by a semi-cylindrical screen. In the latter, triggering activity was progressively distributed throughout the light:dark cycle. The cylindrical screens markedly reduced feed wastage and seabass were able to locate and activate the trigger (even in total darkness) to obtain a reward. $\mathcal{O}$ Ifremer/Elsevier, Paris
\end{abstract}

Fish culture / self-feeding / feed wastage / feeding behaviour

Résumé - Une façon simple d'éliminer le gaspillage d'aliment chez le loup européen, Dicentrarchus labrax, en condition d'auto-alimentation. Les systèmes d'alimentation en libre-service laissent les animaux exprimer librement leur rythme alimentaire. Une simple tige immergée à la surface du bassin sert de levier que les poissons apprennent rapidement à utiliser pour obtenir leur nourriture. Cependant, ce levier proposé à des loups européens expérimentés, Dicentrarchus labrax, peut provoquer un nombre élevé de contacts et un gaspillage d'aliment probablement dû à des contacts involontaires. Des écrans de protection ont été mis au point pour éviter ces contacts au hasard et le gaspillage d'aliment. L'efficacité d'un levier simple a été comparée à celle d'un levier protégé, soit par un écran semi-cylindrique, soit par un écran cylindrique dans des conditions d'auto-alimentation continue (récompense : $0,2 \mathrm{~g}$ de granulé par $\mathrm{kg}$ de poissons et par contact) de juvéniles de loup (poids moyen $57 \mathrm{~g}$ ) pendant 28 jours à $21,3^{\circ} \mathrm{C}$. Le profil d'activité alimentaire journalier sous une photopériode de 4 -h de jour et de 20 -h de nuit (obscurité totale ou non) a été enregistré ainsi que la part de gaspillage nocturne et diurne. Tous les poissons ont présenté une activité alimentaire noctume à l'exception d'un groupe placé en présence d'un écran semi-cylindrique où cette activité s'est équilibrée progressivement entre le jour et la nuit. Seuls les leviers équipés d'un écran cylindrique ont permis une réduction notoire du gaspillage. Dans cette situation, les poissons furcnt capables de localiser et de manipuler le levier dans l'obscurité totale. (C) Ifremer/Elsevier, Paris

Élevage de poissons / auto-alimentation / gaspillage d'aliment / comportement alimentaire

\section{INTRODUCTION}

Solid wastes emanating from intensive fish farming comprise fish faeces and feed wastes, and in extreme cases, feed losses may represent $40 \%$ of the feed delivered to fish $[15,23,27]$.

Feed wastage has both economic consequences for the farmer and a negative environmental impact [26].
Feed wastage will depend on the feeding regime employed [13, 19], and the feeding regimes used in commercial production often represent compromises developed in an attempt to meet the needs of the fish whilst limiting feed waste.

Two methods have been adopted to adapt feeding regimes to the feeding demand of the fish. In the first case, there is an a posteriori control of feed delivery, in

\footnotetext{
* Corresponding author, e-mail: denis.coves@ifremer.fr
} 
that feed is dispensed automatically from feeders and the detection of uneaten pellets controls future feed delivery via a feedback system $[5,8,9,20]$. This demand-feeding concept based on an estimation of fish satiation is mainly used in net-pen cages. In a second approach, fish can freely express feeding behaviours by actuating the trigger mechanism of a self-feeder thereby initiating the release of feed $[1,6,12]$. This feeding system based on fish feeding motivation is more widespread in land-based fish farming.

In the latter, when a recorder is linked to the trigger, the daily feed demand profile can be registered by a computer $[6,12,17,24]$. However, when such a rod is presented to either experienced or unexperienced individuals, huge feed wastage may occur.

If a faecal/waste feed trap added to the rearing tank collects uneaten pellets without monitoring them, only total daily wastage is recorded without any possibility of knowing the moment they occurred. In that case, it becomes impossible to follow the actual feed intake daily profile and only the feed demand one can be monitored. This situation may be an actual bolleneck in experimental conditions and it is, therefore, of prime importance to know the reasons behind feed wastage. During the last 3 years, several practical observations have led us to formulate assumptions (unpublished results).

In 1994, a simple rod was proposed to $150 \mathrm{~g}$ seabass stocked at $50 \mathrm{~kg} \cdot \mathrm{m}^{-3}$ in two $10-\mathrm{m}^{3}$ tanks lighted $16 \mathrm{~h}$ per day at a water temperature of $22^{\circ} \mathrm{C}$. At each fish contact, $0.02 \mathrm{~g}$ of pellet per $\mathrm{kg}$ fish was delivered as a reward. In such conditions, $50 \%$ of feed demands was recorded during the nocturnal period but delivered pellets were almost entirely trapped. As nocturnal feed demands were equally spread among the 8 night-hours, we suspected that the feed waste was the result of unintentional contacts of fish against the trigger during nocturnal swimming close to the water surface. The use of a very simple semi-cylindrical PVC screen to protect the trigger resulted in a decrease in feed losses to $2 \%$ of the daily feed delivery even though $12 \%$ of daily trigger actuations were recorded during the night.

In 1996, we used cylindrical screens to protect the trigger during an experiment dealing with the effect of ammonia level in juvenile seabass feed intake (unpublished results). In the study, $100 \mathrm{~g}$ seabass were stocked at $10 \mathrm{~kg} \cdot \mathrm{m}^{-3}$ in sixteen $1-\mathrm{m}^{3}$ tanks and lighted $16 \mathrm{~h}$ per day for a water temperature of $22^{\circ} \mathrm{C}$. The fish were rewarded with $0.15 \mathrm{~g}$ of food per trigger actuation. In this case, no feed waste was observed no matter the ammonia concentration used.

But, as about $100 \%$ of the triggering activity occurred during the light phase, we suspected that such a cylindrical screen could hide the trigger during the night and involuntarily restrict fish feeding demand to the light phase. If that was the case, this kind of protection screen could not be used to study the diel feeding pattern in fish species, such as seabass, which have a very flexible light-dependent feeding activity [25].
This study aimed at comparing the different trigger protection systems regarding their consequences on feed wastage and their capacity to meet the fish feed demand independently of the nocturnal or the diurnal phase. A nocturnal-dominant photoperiod regime was applied to put the fish in an extreme situation regarding their capacity to actuate the trigger and localise the pellets in total darkness.

\section{MATERIALS AND METHODS}

Prior to transferring the hatchery-reared juvenile seabass into the experiment area, their rearing water temperature was raised from 15 to $18{ }^{\circ} \mathrm{C}$. This temperature was maintained at that level for 2 weeks while the photoperiod was adjusted from $16 \mathrm{~h}-\mathrm{L} / 8 \mathrm{~h}-\mathrm{D}$ to $12 \mathrm{~h}-\mathrm{L} / 12 \mathrm{~h}-\mathrm{D}$ and, then, temperature and photoperiod conditions were maintained for a further 3 weeks to allow the fish to become accustomed to this new situation.

Then, the fish (average body weight $57 \mathrm{~g}$ ) that had experience in self-feeding by using a trigger with a cylindrical screen were initially stocked at about 5$6 \mathrm{~kg} \cdot \mathrm{m}^{-3}$ (100 fish) in circular $1-\mathrm{m}^{3}$ tanks (figure 1 ).

They were fed commercial extruded pellets (Biomar, Ecolife $3 \mathrm{~mm}, 45 \%$ proteins and $21.5 \%$ lipids). Selffeeders based on the design described by Boujard et al. [12] were adjusted to deliver an average reward of $2 \mathrm{~g}$ pellets (one pellet per fish) per trigger actuation, i.e. $0.2 \mathrm{~g}$ per $\mathrm{kg}$ of body weight. Feeders were made freely available to the fish with the exception of a 30-min period (13h30-14h00) during which feed remaining in the feeder was weighed (figure 2).

Each tank (figure l) was covered by an opaque hood, enabling strict control of lighting conditions and ensuring total darkness during the nocturnal phase. Feeders wcre situated outside the hood and feed was led to the tank via a chute. All the tanks were fitted with a sediment trap adapted from Cho et al. [16] to collect uneaten feed. Feed wastage was collected from the sediment traps at

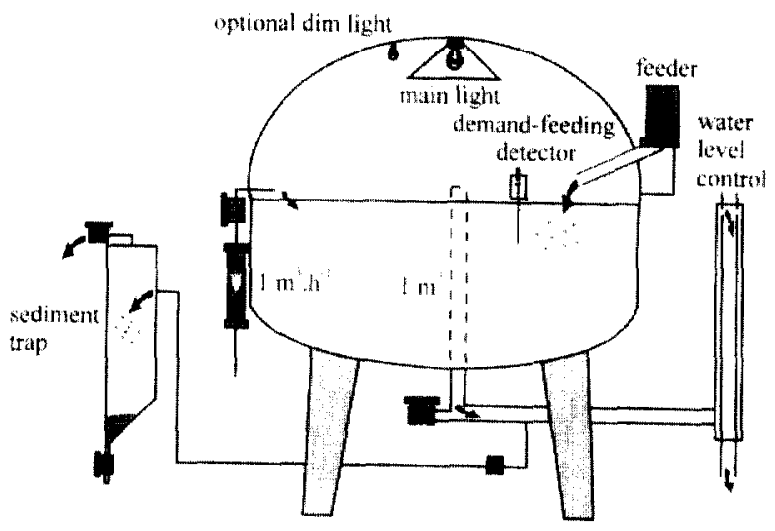

Figure 1. General set-up of tanks showing lighting, feeding, flow rate adjustement and sediment trap devices. 


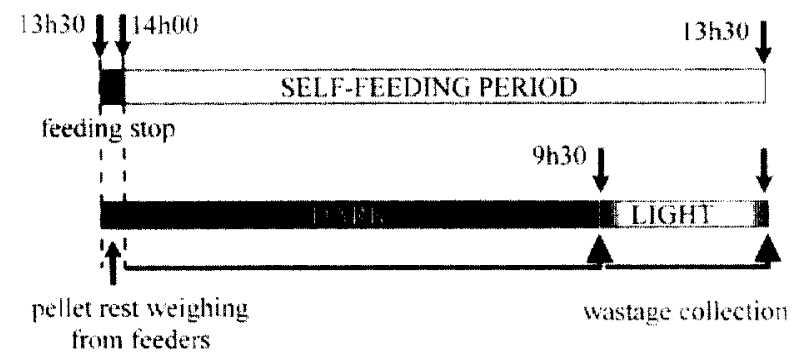

Figure 2. Daily self-feeding, photoperiod and wastage collection schedule.

the end of the light and dark phases and the number of uneaten pellets was counted (figure 2).

Temperature was adjusted at $21.3^{\circ} \mathrm{C}$ in order to stimulate the appetite. For the reasons previously given, an artificial photoperiod of $4 \mathrm{~h}-\mathrm{L} / 20 \mathrm{~h}-\mathrm{D}$ (including half-anhour dawn and half-an-hour dusk, lights on at $09 \mathrm{~h} 30$ ) was applied and maintained using $75-\mathrm{W}$ bulbs. The maximum light intensity provided to the fish was equivalent to a 46-feet candle. Running seawater was used at a flowrate of $1 \mathrm{~m}^{3} \cdot \mathrm{h}^{-1}$ in order to maintain the postprandial oxygen level above $80 \%$ of saturation and a satisfactory self-cleaning of the tank. The average salinity was around 32.5 .

Four basic conditions were compared in 8 tanks organised in pairs. Two tanks received a simple trigger (A), 2 tanks the trigger protected by a semi-cylindrical screen (B), 2 tanks the trigger protected by a cylindrical screen $(\mathrm{C} 1)$, and 2 tanks were identical to $\mathrm{Cl}$ except that the fish were exposed to a low intensity light (4.6-feet candle) provided by a dim light (3.5-W bulbs) during the 'nocturnal' period ( $\mathrm{C} 2)$.

Two trigger positions were successively tested using the simple trigger (A). First, the trigger was immersed $6 \mathrm{~cm}$ from the water surface for 8 days (period one: $\mathrm{P} 1$ ), and then, the trigger was raised $2 \mathrm{~cm}$ for 20 days (period two: $\mathrm{P} 2$ ) in expectance of a limitation of the feed waste observed during P1.

Three rod positions were employed in tests with screened triggers $(\mathrm{B}, \mathrm{Cl}$ and $\mathrm{C} 2): 1 \mathrm{~cm}$ below the screen, and this was maintained 2 days until the fish actuated the trigger (period one: P1). Then, the trigger was raised to be coincidental with the lower limit of the screen for 22 days (P2). Finally, the trigger was raised $1 \mathrm{~cm}$ above the screen limit for 4 days (P3) to test the capacity of the fish to actuate the rod inside the screen.

The following data were collected during the course of the experiment:

(1) Amount (g, dry weight) of daily feed delivered per tank (DDF);

(2) Amount (g, dry weight) of feed delivered during the dark or light phase $=$ number of trigger actuations per phase $\times$ average reward;
(3) Daily uneaten feed (DUF) $=$ number of pellets collected in the sediment trap $\times$ average pellet weight (g, dry weight);

(4) Percentage of feed waste (FW) $=100 \times($ DDUF/ $\Sigma \mathrm{DDF}$ ) for a given time;

(5) Daily feed intake (DFI) = DDF - DUF;

(6) Biomass gain $(\mathrm{BG})=$ final biomass $(\mathrm{FB})-$ initial biomass (IB);

(7) Specific growth rate $(\mathrm{SGR})=100 \times[\ln (\mathrm{FB})-$ $\ln (\mathrm{IB})] /$ days);

(7) Feed:gain ratio (FGR) $=\Sigma D F I$ (g, dry weight) $/$ BG ( $\mathrm{g}$, wet weight);

(8) Average percentage of feed demand per hour $=$ $\Sigma[100 \times$ (actuation number during one given hour/total actuation number during one given day)]/days.

The daily feed demand profile corresponds to the evolution of the average percentage of actuations per hour during $24 \mathrm{~h}$ calculated for a given number of days.

All results are presented as mean \pm standart deviation (SD). A $t$-test or a Mann-Whitney rank sum test was used to compare 2 means. The comparison of several means was assessed by a one-way analysis of variance or a Kruskal-Wallis analysis of variance on ranks. When Fvalues indicated significance, individual means were compared using the Student-Newman-Keuls multiple range test $(P<0.05)[28]$.

\section{RESULTS}

Except for one B tank, in all tanks, the feed daily demand pattern is similar to that presented in figure 3a for a screened trigger $(C)$ during P2. Fish triggered mostly during the dark phase so that more than $95 \%$ of feed was delivered during this phase. In one B tank, the feeding demand profile progressively shifted to a balanced nocturnal/diurnal one during $P 2,13$ days after the beginning of the experiment (figure $3 b$ ).

The evolution of the DDF (figure 4) and of the DFI (figure 5) per tank was different depending on the screen types. The DDF and the DFI curves showed a transition period of 8 and 13 days in tanks $\mathrm{C} 1$ and only 6 days in tanks $\mathrm{C} 2$. In contrast, the lack of screen allowed a quick and relatively high DDF and DFI for the same period of time although the DFI started more slowly in tanks B than in $\mathrm{A}$.

For tanks A, both DDF and DFI were not found to be significantly different between the 2 tanks during $\mathrm{P} 1$ and P2 (table I). Depending on the tanks, FW were 66 and $58 \%$ during P1 and 10 and $23 \%$ during P2.

Considering tanks $\mathrm{B}, \mathrm{C} 1$ and $\mathrm{C} 2$ during $\mathrm{P} 2$, DDF (table I), did not significantly differ between tanks except for one of the tanks B. The comparison of DFI (table $I$ ) between tanks led to the same conclusion. The same tank B differed significantly from the others and was found to producc $44 \%$ of FW while it was close to zero for the other tanks. 


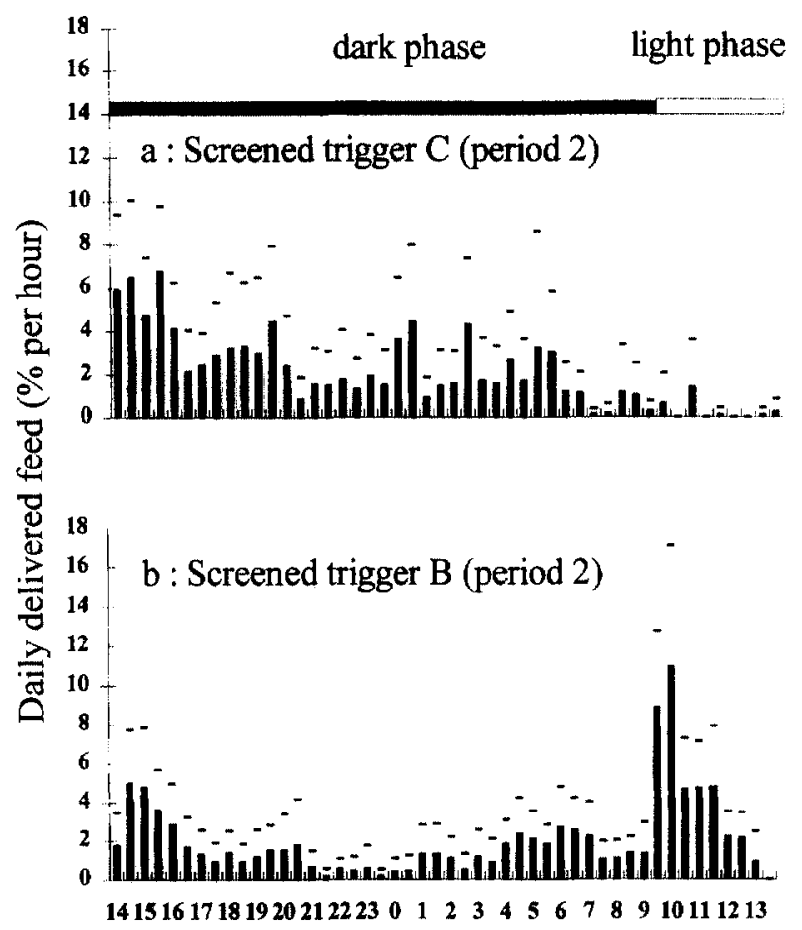

Time clock (hours)

Figure 3. Daily profile of feeding activity. The bars express the average percentage of daily delivered-feed per hour during $\mathrm{P} 2$ for (a) one tank with a screened trigger $C$ and (b) one tank with a screened trigger B. Horizontal dashes indicate the limit of confidence intervals $(n=22$, $\alpha-0.05$ )

During P3, both DDF and DFI (table I) did not differ significantly among these tanks. Only one of the tanks C1 produced $1.2 \% \mathrm{FW}$ compared to 0 for the others.

More than $90 \%$ of the pellet loss occurrence was situated during the nocturnal phase with rare exceptions concerning one tank A during Pl and half of the tanks with a screened trigger during the first 2 days (P1).

The comparison of DFI (table In) among all the tanks after a transition period, i.e. 13 days after the start of the experiment until the end of the experiment, showed that DFI in tanks A and B were significantly higher than DFI of $\mathrm{C} 2$ and one of the tanks $\mathrm{C} 1(P<0.05)$. The FI of the second tank $\mathrm{C} 1$ was situated between these 2 groups.

Finally, during the 28 days that this experiment lasted, the total amount of pellet eaten by tanks $A$ and B ranged between 2800 and $3048 \mathrm{~g}$ while it was between 1824 and $2111 \mathrm{~g}$ in tanks $\mathrm{C} 1$ and $\mathrm{C} 2$ (25 to $40 \%$ less). Only 0.05 to $0.15 \%$ and 2.0 to $4.3 \%$ of the total delivered feed were wasted during the same time in tanks $\mathrm{C} 1$ and $\mathrm{C} 2$ respectively, while 32 to $36 \%$ in tanks A and 6.9 to $45 \%$ in tanks B (table III) were lost.

The SGR, but not the FGR, was significantly and positively influenced by the average feed intake depending on the type of screen used (table $I I I$, figure 6).
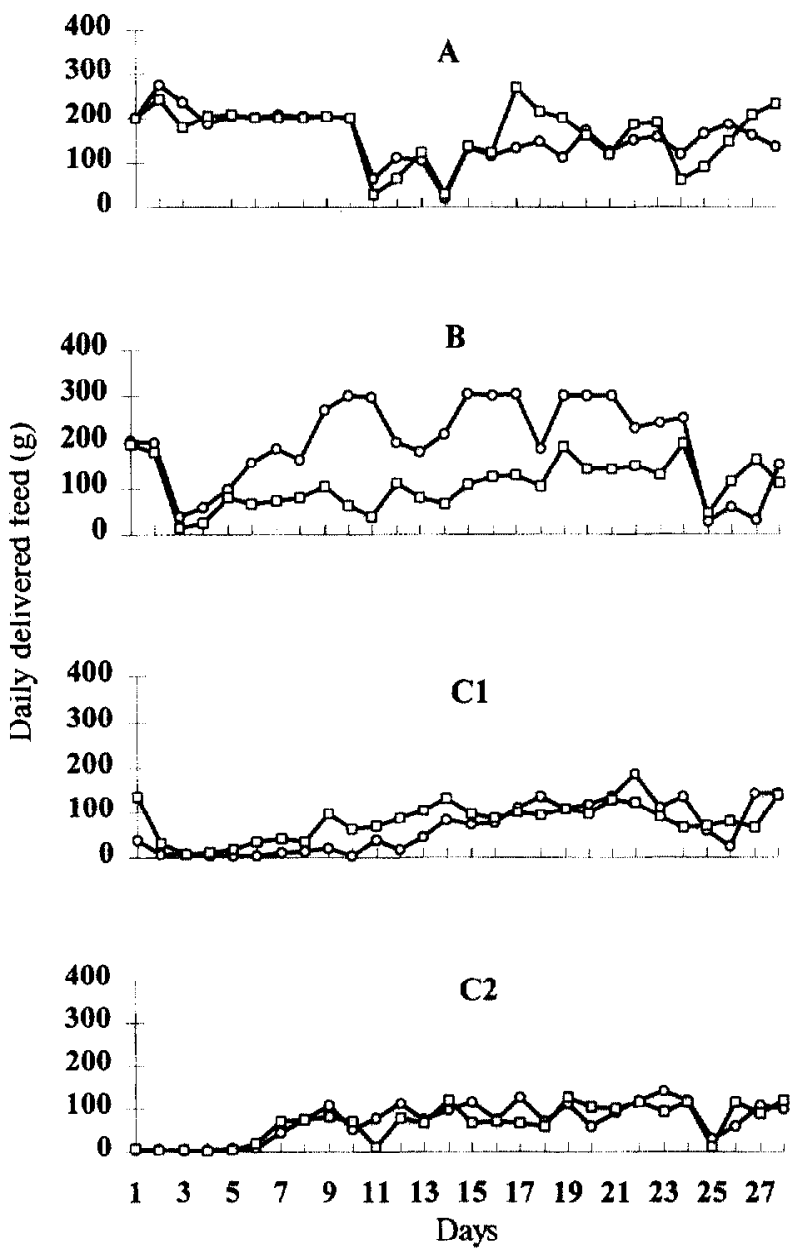

Figure 4. Comparative evolution of the daily-delivered feed in relation to time under each screen condition.

\section{DISCUSSION AND CONCLUSION}

In our experimental conditions, the use of a simple trigger generated important uneaten feed waste until the rod length was raised to $2 \mathrm{~cm}$ from the water surface. Despite the actual improvement due to this position, the amount of wasted, and generally broken up, pellets collected in the sediment trap remained high thereby inducing risks of inaccurately estimating their quantity.

Considering that 1) the uneaten pellets were predominant during the dark phase when the main feed demand occurred and 2) they were found in a very low amount in tanks B and $\mathrm{C}$ which also had a nocturnal feeding activity, we supposed that the feed wastage was due to unintentional actuations of the trigger when the fish were no longer sufficiently hungry to eat all the delivered feed. However, this situation facilitated feed delivery, as early as the first days of the experiment, giving the fish the opportunity of rapidly getting pellets and enabling them to sustain their growth. The 

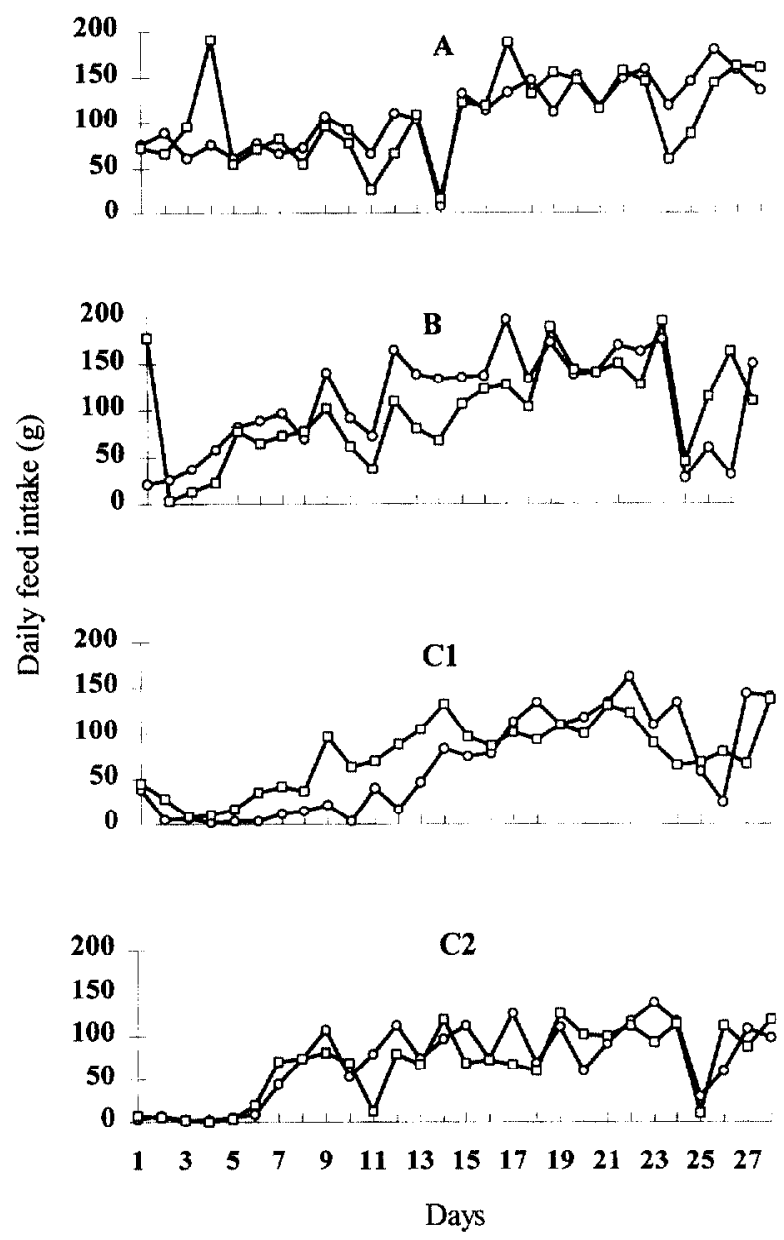

Figure 5. Comparative evolution of the daily feed intake in relation to time under each screen condition.

same results were recorded, but to a lesser extent, with the semi-cylindrical screens.

Despite the fact that the fish were already experienced in using a screened trigger, the actuation of the rod was delayed in the case of tanks $\mathrm{C} 1$ and $\mathrm{C} 2$. This delay showed that the fish needed several days to adjust to the new rearing conditions [7, 21]. After this delay, the triggering activity demonstrated that a cylindrical screen did not prevent the fish from actuating the rod during either the light or the dark phase. It is suggested that seabass is able (1) to localise the screen, (2) to perform a specific action to find the trigger inside the screen and (3) to strike it under any light condition, including total darkness. We can hypothesise that this type of screen contributed to selecting a motivated act in order for fish to feed themselves and resulted in a drastic reduction of feed loss.

This observation gives the opportunity to study seabass feed intake activity, and not only to record the feeding demands no matter the type of photoperiod.

This is particularly interesting for species with a dualism in the diel feeding pattern such as seabass [25].

The differences observed both in terms of delivered and wasted feed within the tanks $B$ have been explained by a bad trigger positioning detected during $P 2$. The trigger was in an oblique position and slightly outside the screen facilitating chance contacts.

As Sànchez-Vàsquez et al. [25] suggested, we agree that sensory organs other than vision, such as the lateral line, are needed in total darkness to localise both the trigger and the delivered pellets [22]. The persistence of a very low amount of uneaten feed during the dark phase in tanks $\mathrm{Cl}$ could show the limits of such organs in localising small pellets ( $3 \mathrm{~mm}$ in size) particularly when they have sunk to the bottom of the tank. This supposition was confirmed by the fact that no pellet was lost when a dim light was used (tanks C2), if we accept that the dim light intensity was above the seabass' visual perception threshold [18].

If a voluntary feeding behaviour can be discriminated by a screened trigger, this system is not an infallible way of stopping feed wastage. The reward size, in terms of delivered pellet weight per fish body weight or delivered pellet number per number of fish, has to be adjusted to the whole population's instantaneous feed intake capacity $[3,4]$. The pellet residence time in the tank (in the water and on the bottom) has to be sufficient to give the fish the opportunity to localise and catch them before they lcave the rearing middle [14]. Fish

Table I. Daily-delivered feed (DDF) and daily feed intake (DFI) for each tank and each period under each experimental condition A, B, C1 and C2.

\begin{tabular}{|c|c|c|c|c|c|c|c|c|}
\hline & \multicolumn{2}{|c|}{ A } & \multicolumn{2}{|c|}{ B } & \multicolumn{2}{|c|}{$\mathrm{Cl}$} & \multicolumn{2}{|c|}{$\mathrm{C} 2$} \\
\hline & $\mathrm{Pl}(n=8)$ & $\mathrm{P} 2(n=20)$ & $\mathrm{P} 2(n=22)$ & P3 $(n=4)$ & $\mathrm{P} 2(n=22)$ & $\mathrm{P} 3(n=4)$ & $\mathrm{P} 2(n=22)$ & $\mathrm{P} 3(n=4)$ \\
\hline \multicolumn{9}{|l|}{ DDF $(g)$} \\
\hline $\begin{array}{l}\text { Tank } 1 \\
\text { Tank } 2\end{array}$ & $\begin{array}{l}214 \pm 29 \\
204 \pm 18\end{array}$ & $\begin{array}{l}135 \pm 43 \\
149 \pm 69\end{array}$ & $\begin{array}{l}221 \pm 82^{a} \\
100 \pm 48^{b}\end{array}$ & $\begin{array}{r}67 \pm 58 \\
108 \pm 48\end{array}$ & $\begin{array}{l}66 \pm 57^{h} \\
77 \pm 38^{h}\end{array}$ & $\begin{array}{l}93 \pm 61 \\
88 \pm 64\end{array}$ & $\begin{array}{l}76 \pm 43^{b} \\
69 \pm 39^{b}\end{array}$ & $\begin{array}{l}74 \pm 37 \\
83 \pm 50\end{array}$ \\
\hline \multicolumn{9}{|l|}{ DFI $(\mathrm{g})$} \\
\hline $\begin{array}{l}\text { Tank } 1 \\
\text { Tank } 2\end{array}$ & $\begin{array}{l}72 \pm 9 \\
85 \pm 44\end{array}$ & $\begin{array}{l}121 \pm 37 \\
113 \pm 46\end{array}$ & $\begin{array}{r}124 \pm 43^{a} \\
99 \pm 48^{b}\end{array}$ & $\begin{array}{r}67 \pm 58 \\
108 \pm 48\end{array}$ & $\begin{array}{l}64 \pm 55^{b} \\
77 \pm 38^{b}\end{array}$ & $\begin{array}{l}92 \pm 60 \\
88 \pm 64\end{array}$ & $\begin{array}{l}76 \pm 43^{b} \\
69 \pm 39^{b}\end{array}$ & $\begin{array}{l}74 \pm 37 \\
83 \pm 50\end{array}$ \\
\hline
\end{tabular}

Considering DDF and DFI separately, means with different superscript letters are significantly different within the same period $(P<0.05)$ for the conditions $\mathrm{B}, \mathrm{C} 1$ and $\mathrm{C} 2$. 
Table II. Daily feed intake (DFI, $n=15$ ) after the transition period in each tank for each experimental condition $\mathrm{A}, \mathrm{B}, \mathrm{Cl}$ and $\mathrm{C} 2$.

\begin{tabular}{|c|c|c|c|c|c|c|c|c|}
\hline & \multicolumn{2}{|c|}{$A$} & \multicolumn{2}{|c|}{ B } & \multicolumn{2}{|c|}{$\mathrm{C} 1$} & \multicolumn{2}{|c|}{$\mathrm{C} 2$} \\
\hline & Tank 1 & Tank 2 & Tank 1 & Tank 2 & Tank 1 & Tank 2 & Tank 1 & Tank 2 \\
\hline DFI (g) & $130 \pm 39$ & $126 \pm 44^{a}$ & $131 \pm 51$ & $127 \pm 40^{4}$ & $108 \pm 38^{b}$ & $98 \pm 24^{c}$ & $94 \pm 30^{c}$ & $91 \pm 31^{\circ}$ \\
\hline
\end{tabular}

Means with different superscript letters are significantly different $(P<0.05)$.

Table III. Global biological performances registered during the 28 days of the experiment in the 2 tanks under each condition $\mathrm{A}, \mathrm{B}, \mathrm{C} 1$ and $\mathrm{C} 2$.

\begin{tabular}{|c|c|c|c|c|c|c|c|c|}
\hline & \multicolumn{2}{|c|}{ A } & \multicolumn{2}{|c|}{ B } & \multicolumn{2}{|c|}{$\mathrm{C} 1$} & \multicolumn{2}{|c|}{$\mathrm{C} 2$} \\
\hline & Tank 1 & Tank 2 & Tank 1 & Tank 2 & Tank 1 & Tank 2 & Tank 1 & Tank 2 \\
\hline IB $(\mathrm{g})$ & 5386 & 5436 & 5472 & 5361 & 5476 & 5383 & 5717 & 5607 \\
\hline $\mathrm{FB}(\mathrm{g})$ & 8170 & 7897 & 7915 & 7928 & 6880 & 7039 & 7677 & 7369 \\
\hline $\mathrm{BG}(\mathrm{g})$ & 2784 & 2461 & 2443 & 2567 & 1404 & 1656 & 1960 & 1762 \\
\hline$\Sigma D D F(g)$ & 4418 & 4607 & 5544 & 3007 & 1862 & 2207 & 1981 & 1857 \\
\hline$\Sigma \mathrm{DFI}(\mathrm{g})$ & 3001 & 2953 & 3048 & 2800 & 1824 & 2111 & 1978 & 1856 \\
\hline FW $(\%)$ & 32 & 36 & 45 & 6.9 & 2.0 & 4.3 & 0.15 & 0.05 \\
\hline FGR & 1.08 & 1.20 & 1.25 & 1.09 & 1.30 & 1.27 & 1.01 & 0.90 \\
\hline SGR $\left(\% \cdot\right.$ day $\left.^{-1}\right)$ & 1.34 & 1.20 & 1.19 & 1.26 & 0.74 & 0.87 & 0.95 & 0.88 \\
\hline
\end{tabular}

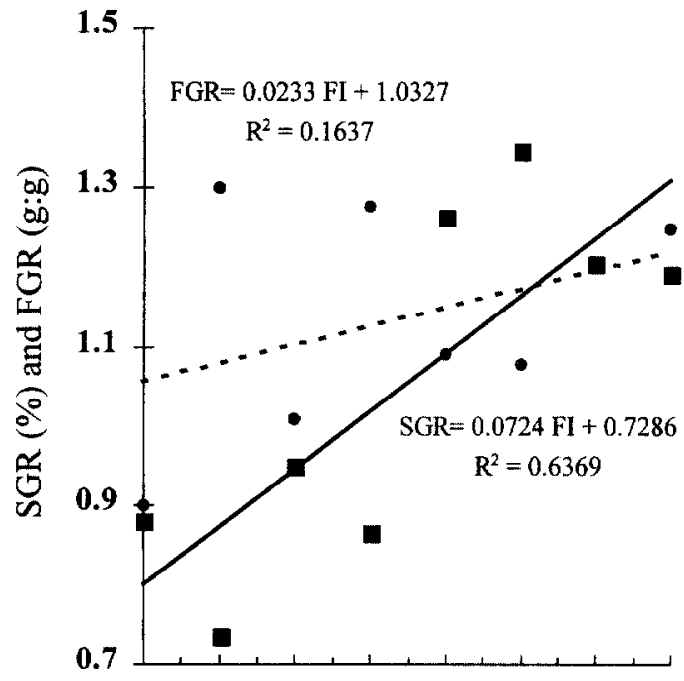

$\begin{array}{llllllll}0.87 & 1.05 & 1.05 & 1.21 & 1.51 & 1.58 & 1.58 & 1.63\end{array}$

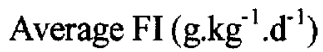

Figure 6. Specific growth rate (-D. SGR) and feed:gain ratio (FGR) plotted against the daily average feed intake (FI). dominance interaction or fish density may also reduce access to pellets and induce wastage.

Unfortunately, this too short-lasting experiment, which included an adaptation time, did not allow the comparison of long-term efficacy of each triggering systems in terms of growth and feed:gain ratio.

Taking into account these previous reservations, we conclude that a cylindrical screened trigger is an effective way, among others $[2,3,10,11]$, to avoid chance contacts and hence limit or stop feed losses under experimental conditions. In fact, screened triggers have been successfully proposed for 3 years to seabass ranging between $2.5 \mathrm{~g}$ and $1 \mathrm{~kg}$ (body weight) reared in $10-\mathrm{m}^{3}$ tanks and stocked between 50 and $150 \mathrm{~kg} \cdot \mathrm{m}^{-3}$ (unpublished results). Fish had unrestricted access to one feeder under a $16 \mathrm{~h}-\mathrm{L} / 8 \mathrm{~h}-\mathrm{D}$ photoperiod at $22^{\circ} \mathrm{C}$. Less than $1 \%$ of the daily delivered pellets was lost and collected in the faecal/waste feed trap, showing that such a simple device can be adjusted and save feed waste in fish IIlass production.

This advantage and the possibility to study feed intake rhythms on a continuous basis have to be considered for species other than seabass.

\section{Acknowledgements}

The authors would like to thank Dr T. Boujard for having kindly placed his expertise in self-feeding at their disposal and the organising committee of the IIIrd Nutritional Strategies and Management of Aquaculture Waste International Symposium in Vila Real (Portugal, October 1-4, 1997) where these results were presented as an oral communication. 


\section{REFERENCES}

[1] Adron J.M., A design for automatic and demand feeders for fish, J. Cons. Perm. Int. Explor. Mer 34 (1972) 300-305.

[2] Alanärä A., Demand feeding as self-regulating system for rainbow trout (Oncorhynchus mykiss) in net pens, Aquaculture 108 (1992) 347-356.

[3] Alanärä A., The effect of temperature, dietary energy content and reward level on feeding activity, growth and feed conversion in rainbow trout (Oncorhynchus mykiss), Aquaculture 126 (1994) 349-359.

[4] Alanärä A., Kiessling A., Changes in demand feeding behaviour in Arctic charr, Salvelinus alpinus L., caused by differences in dietary energy content and reward level, Aquac. Res. 27 (1996) 479-486.

[5] Ang K.P., Petrell R.J., Control of fecd dispensation in sea cages using underwater video monitoring: effects on growth and food conversion, Aquac. Eng. 16 (1997) $45-62$.

[6] Anthouard M., Wolf V., A computerized surveillance method based on self-feeding measures in fish populations, Aquaculture 71 (1988) 151-158.

[7] Anthouard M., Desportes C., Kentouri M., Divanach P., Paris $P_{.}$, Étude des modèles comportementaux manifestés au levier par Dicentrarchus labrax, Diplodus sargus, Puntazzo puntazzo, Sparus aurata, et Lithognathus mormyrus (poissons téléostéens), placés dans une situation de nourrissage auto-contrôlé, Biol. Behav. 11 (1986) 97-110.

[8] Blyth P.J., Purser J.G., Russel J.F., Detection of feeding rhythms in sea caged Atlantic salmon using new feeder technology, in: Reinertsen H., Dahle L.A., Jørgensen L., Tvinnereim K. (Eds.), Fish Farming Technology, Trondheim, 1993, pp. 203-208.

[9] Blyth P.J., Purser J.G., Russel J.F., Progress in fish production technology and strategies: with emphasis on feeding, Suisanzoshoku (1997) 151-161.

[10] Boujard T., Leatherland J.F., Demand feeding behaviour and dicl pattern of feeding activity in Oncorhynchus mykiss held under different photoperiod regimes, J. Fish Biol. 40 (1992) 535-544.

[11] Boujard T., Moreau Y., Luquet P., Entrainment of the circadian rhythm of food demand by infradial cycles of light-dark alternation in Hoplosternum littorale (Teleostei), Aquat. Living Resour. 4 (1991) 221-225.

[12] Boujard T., Dugy X., Genner D., Gosset C., Grig G., Description of a modular, lowcost eater meter for the study of feeding behavior and food-preferences in fish, Physiol. Behav. 52 (1992) 1101-1106.

[13] Brännäs E., Alanärä A., Feeding behaviour of the Arctic charr in comparison with the rainbow trout, Aquaculture 105 (1992) 53-59.

[14] Brännäs E., Alanärä A., Effect of reward level on individual variability in demand feeding activity and growth rate in Arctic charr and rainbow trout, J. Fish Biol. 45 (1994) 423-434.

[15] Chen S., Coffin D.E., Malone R.F., Production, characteristics, and modeling of aquacultural sludge from a

Aquat. Living Resour. 11 (6) (1998) recirculating aquacultural system using a granular media biofilter, in: Wang J.K. (Ed.), Techniques for Modern Aquaculture, Proc. Aquacultural Engineering Conference, American Society of Agricultural Engineers Publishers, Spokane, Washington, 1993, pp. 1625.

[16] Cho C.Y., Slinger S.J., Bayley H.S., Bioenergetics of salmonid fishes: energy intake, expenditure and productivity, Comp. Biochem. Physiol. 73B (1982) 25-41.

[17] Cuenca E.M., de la Higuera M., A microcomputer-controlled demand feeder for the study of feeding behavior in fish, Physiol. Behav. 55 (1994) 1135-1136.

[18] Douglas R.H., Hawryshyn C.W., Behavioural studies of fish vision: an analysis of visual capabilities, in: Douglas R.H., Djamgoz M.B.A. (Eds.), The visual system of fish, Chapman and Hall Publishers, New York, USA, 1990, pp. 373-418.

[19] Jørgensen E.H., Baardvik B.M., Eliassen B.M., Jobling M., Food acquisition and growth of juvenile Atlantic samon (Salmo salar) in relation to spatial distribution of food, Aquaculture 143 (1996) 277-289.

[20] Juell J.E., Furevik D.M., Bjordal A., Demand feeding in salmon farming by hydroacoustic food detection, Aquac. Eng. 12 (1993) 155-167.

[21] Kentouri M., Anthouard M., Divanach P., Paspatis P., Les modalités d'adaptation comportementale de populations de bars (Serranidae : Dicentrarchus labrax) soumises à un nourrissage auto-contrôlé, Ichthyophysiol. Acta 15 (1992) 29-42.

[22] Montgomery J.C., Milton R.C., Ise of lateral line for feeding in the torrentfish (Cheimarrichthys fosteri), New Zealand J. Zool. 20 (1993) 121-125.

[23] Raa I., Liltved H., An assessment of the compatibility between fish farming and the Norwegian coastal environment, in: De Pauwn J. (Ed.), Europ. Aquac. Soc. Spec. Publ. n 16, Gent, Belgium, 1991, pp. 51-59.

[24] Sánchez-Vásquez F.J., Martínez M., Zamora S., Madrid J.A., Design and performance of an accurate demandfeeder for the study of feeding behaviour in seabass, Dicentrarchus labrax L., Physiol. Behav. 56 (1994) 789-794.

[25] Sánchez-Vásquez F.J., Madrid J.A., Zamora S., Circadian rhythms of feeding activity in seabass, Dicentrarchus labrax L.: dual phasing capacity of diel demandfeeding pattern, J. Biol. Rhythms 10 (1995) 256-266.

[26] Thorpe J.E., Cho C.Y., Minimising waste through bioenergetically and behaviourally based feeding strategies, in: Cowey C.B. (Ed.), Nutritional Strategies and Management of Aquaculture Waste, 2nd Int. Symp., Rebild, Denmark 24-27 April, 1994, Elsevier Science Ltd Publishers, Oxford, UK, Water Sci. Technol. 31 (1995) 29-40.

[27] Thorpe J.E., Talbot C., Miles M.S., Rawlings C., Keay D.S., Food consumption in 24 hours Atlantic salmon (Salmo salar L.) in a sea cage, Aquaculture 90 (1990) $41-47$.

[28] Zar J.H., Biostatistical analysis, 3rd ed., Prentice Hall, New Jersey, 1996, 662 p. 